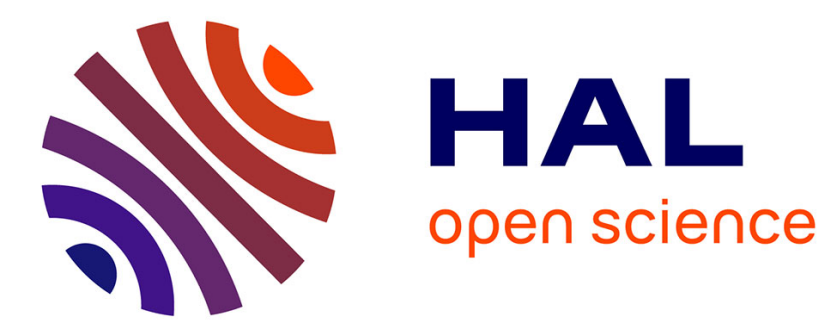

\title{
Project Execution Strategy and Planning Challenges
}

Kristina Kjersem, Gabriele H. Jünge, Jan Emblemsvåg

\section{To cite this version:}

Kristina Kjersem, Gabriele H. Jünge, Jan Emblemsvåg. Project Execution Strategy and Planning Challenges. IFIP International Conference on Advances in Production Management Systems (APMS), Sep 2017, Hamburg, Germany. pp.243-250, 10.1007/978-3-319-66926-7_28 . hal-01707302

\section{HAL Id: hal-01707302 \\ https://hal.inria.fr/hal-01707302}

Submitted on 12 Feb 2018

HAL is a multi-disciplinary open access archive for the deposit and dissemination of scientific research documents, whether they are published or not. The documents may come from teaching and research institutions in France or abroad, or from public or private research centers.
L'archive ouverte pluridisciplinaire HAL, est destinée au dépôt et à la diffusion de documents scientifiques de niveau recherche, publiés ou non, émanant des établissements d'enseignement et de recherche français ou étrangers, des laboratoires publics ou privés.

\section{(c)(1)}

Distributed under a Creative Commons Attribution| 4.0 International License 


\title{
Project Execution Strategy and Planning Challenges
}

\author{
Kristina Kjersem¹, Gabriele H. Jünge², Jan Emblemsvåg1 \\ ${ }^{1} \mathrm{M} \varnothing$ reforsking Molde AS, Norway \\ kristina.kjersem@himolde.no \\ emblemsvag@y ahoo.com \\ ${ }^{2}$ Norwegian University of Science and Technology, Trondheim, Norway \\ gabriele.h.junge@ntnu.no
}

\begin{abstract}
The planning process in Engineer-To-Order (ETO) projects is challenging due to: global network of participants within a project, dynamic iterations on design and en gineering activities as well as the need for completing activities in a concurrent manner that shorten the delivery time. Moreover, managerial decisions on what and where to outsource disturbs the planning process due to lack of integration between different working methodologies or systems. In this article, we present some of the challen ges faced during the planning process and connect them to the project execution strategy applied by ETO companies when managing their projects.
\end{abstract}

Keywords: Project planning, project management, engineer-to-order

\section{Introduction and background}

Generally, a project endeavor implies a temporary organization that requires an administrative and managerial framework, which according to [1], is defined as project governance model. In our paper, we refer to the management segment within the governance model [2] and do not consider the ad min istrative part, which is performed by each organization by following own internal rules and regulations. Within this management segment, which we identify as Project Execution Strategy (PES), we analy ze how the decision process approached at this level affect the project planning and control activities. PES is defined as management tactics applied by project-organized companies to plan, control and complete a project according to customer requirements [3]. The decision on which type of PES to apply is based in most of the cases on issues like 1) the size of the company and its position on the specific market; 2) the necessity to lower total project cost; 3 ) search for new and specialized knowledge, etc. [4]. However, based on our research it seems that most of the ETO companies do not consider how their choice of PES affects their planning process. As such, many project organized companies plan their projects by assuming that they either 1) have control over the whole project and plan its activities at a level that do not consider the effect of dependencies between participating organizations, or 2) they plan only the phases they are responsible for without considering the rest of the phases. In both cases, the result is a rigid planning process where each organization participating in

adfa, p. 1, 2011.

(C) Springer-Verlag Berlin Heidelberg 2011 
the project optimize own activities at the expenses of the project as a whole. Consequently, most ETO projects lack a clear overview over the project status, which, in turn results in cost overruns that could have been avoided through a planning and control process that considers the choice of PES.

In this article we continue the work published at APMS 2016, where we proposed a classification of ETO companies based on their approaches to PES [3]. Through several of our research projects, we mapped PES for ten Norweg ian ETO companies and the categories identified are: 1) vertically integrated type of company, 2) design and engineering, 3) production and testing type [3]. The first category owns most of the processes in each project phase. They acquire s maller local or g lobal companies that deliver services or products able to increase companies' competitive advantage. As a result, their PES seems more integrated and gives better possibilities for control and improvement. The second category contains companies that own only concept, design and detail engineering part of a project. The third category contains companies that focus on core competencies like production and testing the final product. The ETO aspect of the third category lays in their ability to define engineering solutions coming from practical experience and they reveal a good understanding and translation of customer requirements into practice.

Each case company uses different approaches to the planning and control activities and all of them have ongoing projects that are looking on improvement possibilities. The scope of this paper is to increase awareness on the importance of adapting project-planning strategies to the particularities of each PES approach. Based on our case studies, we learned that challenges within the project planning are a direct result of the strategies used for completing each phase of an ETO project.

We analyzed ETO companies producing different types of customized products (ships, cranes, etc.) and we found that applying traditional project planning methods does not consider the choice of PES [3]. Furthermore, considering that more than 75 percent of the ETO product's value is built by involving suppliers of products and services [5], the importance of choosing the right planning process and methodology is important. The tactical decisions made by the project team regarding whom (what scope of work under which terms) will complete what within a project, has major ramifications on the probability of success or failure of the planning process. Thus, the main research question is what are the main challenges posed by the PES to the project planning process in the ETO environment.

\section{Theoretical background}

In this section, we first introduce some relevant features and challenges when managing ETO projects. Then, in our attempt to structure the challenges for each type of PES, we introduce nine characteristics of an effective ETO project planning process.

\subsection{ETO and project management}

Due to an increasing demand for customized products, the number of ETO companies is growing at a fast pace [6] and advances in technology will intensify this pace even more. ETO is a type of production strategy where research and design activities are an 
important part of the project especially during the conceptual phase [7] when the customers define the specific features of the final product. ETO companies face great pressure to reduce cost, shorten lead-time, and maintain high quality while customers increase the complexity of their requirements. The main characteristics of ETO approach are project-based deliveries of products with a high degree of customization in low volumes [8]. Most ETO products are complex and, unlike other types of production approaches, customers are involved at a detailed level throughout the design, procurement and production processes. Such complexity requires often a project team that contain members from a selection of specialized companies that must work together to meet specific requirements [9]. Hence, most ETO companies use project management approaches to manage such teams. Nevertheless, the success or failure of a project is not completely under the control of the project leader and her/his team [2]. Project management literature recommends taking into consideration each project's cultural, social and physical environmental context while the same literature rarely discuss the project context and lack recommendations on "how to act, react or interact" (p. 33) to the context of a project [10]. Another focus area within project management literature is the planning process which is based on a linear strategy that implies dependent, sequential phases [11] executed according to the project plan. Moreover, project management literature does not discuss planning challenges for ETO projects characterized by iterative process, network organized projects and concurrent activities [12]. Thus, most ETO companies using standard project management approaches struggle to achieve a good overview over the status of the project [13]. Then, the fact that there are several suppliers participating in an ETO projects and each might have a different planning software, achieving an overall clear status of the project becomes challenging. To our knowledge, the planning challenges related to the PES are not discussed within the project management literature in any significant degree. Therefore, through the research presented in this paper we contribute to increase the body of knowledge concerning the need to adapt the project planning process to the context of the project, in our case the choice of PES.

\subsection{Characteristics of an effective planning approach}

According to [14], there are nine important characteristics of an effective project planning process within ETO environment: 1) Flexibility refers to the frequency of updating and modify ing the project plan with actual data, which is a challenge when several different suppliers complete a large part of the project. 2) High level of integration of project disciplines is about effectiveness and efficiency of the communication process among project participants. 3) Collaborative planning process is about the project plan created through agreement between project manager and each discipline team leader (not only top-down approach). 4) Effective planning meetings refers to meetings where project participants have the opportunity to effectively inform and be informed about relevant issues on the project status. 5) Good performance measurement system that inform project management team about the status (progress, hours used per activity and remaining budget) of the project. 6) Good progressmeasurement tool that can indicate real progress of the production process. 7) Effective re-planning process indicating whom, when and how fast delayed activities can 
be completed to recover the project plan. 8) Impact analyzing refers to an increased awareness of interdependencies among project participants (visualized through a good planning process ). 9) Lessons learned from project to project can be a difficult task in project organizations especially when these organizations are spread across several countries [14]. Therefore, most ETO projects are managed through a phase-based project manage ment [15], approach. The scope of the characteristics presented here is to illustrate the main areas of a planning process affected by the adapted type of PES.

\section{Methodology}

The ten companies followed in this study are involved in different research projects with our affiliations. Most of these projects focus on improving project management strategies through better planning processes and procedures. However, during our research we learned that even though some of their problems seem similar, their root causes were different and they needed different tactics to the improvement process. Then, we mapped the project phases and the approaches used for completing them. While some of the companies were controlling more or less all phases, others outsourced several phases, so we took a closer look at these differences and their causes. We started by analyzing how the project is planned, where each project phase is executed and by whom. Based on these findings, we started an exploratory case study, which seemed suitable for this type of research [16, 17]. As [17, 18] state, qualitative case studies are suited for acquiring knowledge from practitioners and use them to improve existing theories or develop new ones. Further, exploratory designs are suitable in studies that address issues not yet thoroughly researched, aiming to extend emergent theory [19]. From our studies, we learned that the issue of project planning and control in ETO industry needs more research due to specific challenges within this type of production. Some of the research projects are still ongoing and we work on developing planning processes that consider the PES applied by these case companies. The authors were directly involved in improving project planning processes at three of the case companies. Through the work on these projects, we noted that implementing new planning processes was dependent on the control each company had on each of the project phases as well as on their relations towards the rest of the participating organizations. Thus, we started to search for solutions to improve the project planning process for each type of PES. In addition to the direct participation in several planning meetings, we also collected data through direct interviews, minutesof-meetings and planning documents. We then analyzed the data and identified three main PES for ETO projects and several approaches to the planning process. The results were then discussed with employees from the case companies and their comments were integrated in our findings.

\section{Three types of PES and planning challenges}

The idea for this research comes from our work with ETO companies that are preoccupied to improve the results of their projects by focusing on the planning methods used to manage these projects. One case company preoccupied by improving own 
project management results, started actually a project called "Project Execution Strategy" through which they identified several different in formal PES that were dependent on project leaders' capability, teams expertize, organizational cultures and the level of involvement of suppliers within the project. While improving the internal processes was relatively easy, integrating all participating organizations proved to be challenging due to issues like trust among project participants, different software that are difficult to integrate, different applications and hierarchies within the planning process, interdependencies with suppliers, and so on. The company formulated procedures that could integrate supplier's deliveries within the planning process and create a better collaboration and commitment among the project participants. They also analyzed each project phase and defined criteria that helped project managers decide which activities to be performed by suppliers and which ones will be completed internally. Most case companies have similar improvement projects that focus on better planning and control. However, due to a lack of control over all project phases, improving the project planning process proved challenging.

\subsection{Phase-based project management}

The three types of PES identified in our previous research are based on the project phases described in figure 1 [3]. In the conceptual phase, the customer together with the sale agents establish the main features and performances of the product. These are developed further during the basic design phase, which, together with procurement, generate the basis for detail engineering in $2 \mathrm{D}$. The information from these drawings is conversed to the engineers working with the $3 \mathrm{D}$ model of the product. Customers' approval of the model triggers the completion of the production drawings that contain a higher level of details. Upon the completion of the production drawings, the fabrication process can start. This is followed by the outfitting and commissioning (testing) phases that are completed before the delivery of the final product.

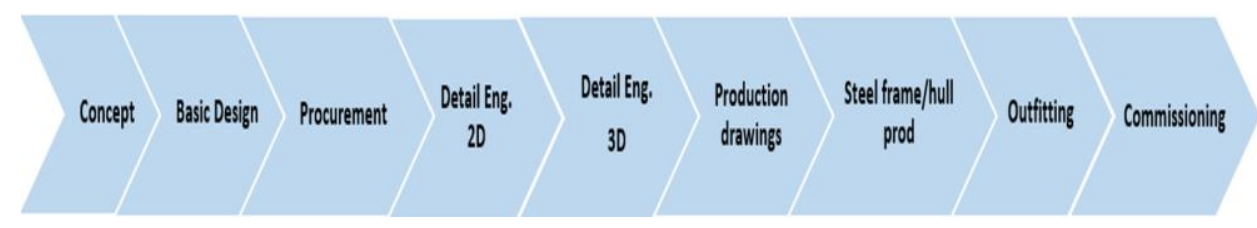

Fig. 1. Phase-based project management [3]

Many of the phases described here are either handled internally (specialized daughter companies) or by suppliers. Most phases are completed more or less concurrently due to pressure on the lead-time [3] and close collaboration between customer and project team. Indeed, many of the companies try to work according to concurrent engineering principles while the contract with the customer is normally phased-based in the sense that there are clear milestones on payments and phases at the top level. This creates a tension in the project between the contractual obligations and the physical realities in the project. Skillful project planning is necessary to facilitate this duality.

The strategies about what and how to outsource in these phases differ among our case companies. So me of the m choose to outsource only some components and minor 
activities, while others outsource all the phases before the production. In the vertically integrated approach, the case companies have good overview over the whole process and are capable of involving external suppliers to a high degree. The design and engineering type has a good overview over the first part of the process and are highly dependent on good feedback from the companies responsible for the rest of the process. The production and testing type would have a good overview over the second part of the process and are therefore highly dependent on technical information from the company delivering design and detail engineering.

\subsection{Challenges for each category}

Considering the nine characteristics of an effective planning process, we studied the effect of PES on each one of them and we summarized the results in the table1.

Table 1. Effects of PES on planning characteristics

\begin{tabular}{|c|c|c|c|c|c|c|c|c|c|}
\hline $\begin{array}{l}\text { PES/ } \\
\text { Planning } \\
\text { Characteristics }\end{array}$ & 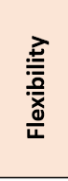 & 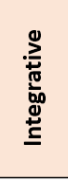 & $\begin{array}{l}\frac{0}{2} \\
\frac{1}{\pi} \\
0 \\
0 \\
\frac{0}{0} \\
0 \\
0\end{array}$ & 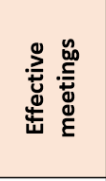 & 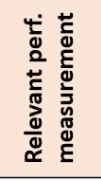 & 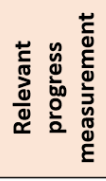 & 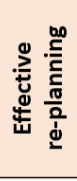 & 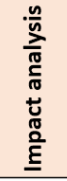 & 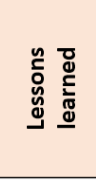 \\
\hline $\begin{array}{l}\text { Vertical } \\
\text { integrated }\end{array}$ & High & High & High & High & High & High & High & High & High \\
\hline $\begin{array}{l}\text { Design and } \\
\text { engineering }\end{array}$ & Low & Low & Low & Partially & Partially & Partially & Low & Low & Partially \\
\hline $\begin{array}{l}\text { Production \& } \\
\text { commissioning }\end{array}$ & Low & Low & Low & Partially & Partially & Partially & Low & Low & Partially \\
\hline
\end{tabular}

From a planning perspective, it seems the vertically integrated type of company has better possibilities for achieving an effective project planning process. These companies were originally relying on significant amount of tacit knowledge, which kept them agile but prone to mistakes as performance was very people dependent. The response to this was twofold. One is that the company itself moves in the direction of improving its process control through formalization of processes, roles, systems and organizational structures. The other response is to outsource work to low cost countries by acquiring specialized companies. The planning process within a vertically integrated PES needs less alterations compared with the othertwo categories.

Within the two other categories, we identified challenges like low flexibility in updating the project plan due to lack of trust in sharing sensitive data as well as different software used for the planning process. They have several participating organization, but low integration. This is because everyone has to deliver according to contractual milestones even when there has been accumulating significant deviations from all parties. Each of the organizations participating in the project create own plans (based on contractual specifications) and have very little connection with the plans from the other participants. Besides, they are usually interested in optimizing their own planning process and that reduces the possibility to achieve an integrated project plan. In table 1, we defined some of the characteristics as partially implemented by the case companies. That is a characteristic, which is common in one or several of the organi- 
zations involved in a project, but they do not comply with the project in its entirety. Thus, some phases of a project can be well executed, but the project suffers delays and budget overruns due to lack of a good overview over the whole project. Replanning delayed activities that affect other activities, impact analyzing and lesson learned are slower and briefer than in vertically integrated PES. Another challenge is lack of feedback between organizations, which is an important aspect when aiming for developing new products. The challenges for the planning process in these types of PES are many. However, one advantage is that they need smaller organizations and the customer can decide who supplies design and who will produce it.

\section{Discussion and further recommendations}

We based our research findings on case studies within a Norwegian context. There is need for further research to gather empirical data from other ETO companies, challenged by a different context, to strengthen the validity of the findings.

The cases studied in this article are all ETO companies preoccupied to improve their project planning processes. In our research, we identified some of the challenges connected to the characteristics of an effective project planning process and the way these are affected by the PES. Based on our findings we argue for the need for a better planning process and one way to improve it is to consider the context of a project that is determined by the choice of PES. However, the organizations responsible for delivering the final product continue to create project plans that imply a good overview over the project status even when they have little or no control over deliveries from the rest of the suppliers. It is not possible for all companies to implement a vertical integrated PES. However, an understanding of the role of PES when planning a project can help these companies identify better approaches to more effective project planning. One approach would be more focus on coordination [20] of these projects and earlier supplier involvement during the project planning process [21].

Our research project is still ongoing and we work on developing project-planning methods that take into consideration the PES and their challenges. The next step of the research would be to test these methods at some of the case companies and present the results in a future article.

\section{References}

$1 \quad$ Zwikael, O., and Smyrk, J.: 'Project governance: Balancing control and trust in dealing with risk', International Journal of Project Management, 2015, 33

2 Too, E.G., and Weaver, P.: 'The management of project management: A conceptual framework for project governance', International Journal of Project Management, 2014, 32, pp. 1382-1394

3 Kjersem, K., and Jünge, G.H.: 'Categorizing Engineer-To-Order Companies through their Project Execution Strategy': 'Advances in Production Management Systems' (IFIP 2016)

$4 \quad$ Nujen, B.B., and Halse, L.L.: 'Global shift-back's: A strategy for reviving manufacturing competencies ', Advances in International Management 2017, 30 
5 Dubois, A., and Gadde, L.-E.: 'Supply strategy and networks effects purchasing behaviour in the construction industry ', European Journal of Purchasing \& Supply Management, 2000, 6, pp. 207-215

6 Grabenstetter, D.H., and Usher, J.M.: 'Sequencing jobs in an engineer-toorder engineering environment ', Production \& Manufacturing Research: An Open Access Journal 2015, 3, (1), pp. 201-217

7 Questica, E.: 'Positioning engineer-to-order companies to compete in a growing industry ', in Editor (Ed.) $)^{\wedge}(\mathrm{Eds}$.$) : 'Book Positioning engineer-to-order$ companies to compete in a growing industry' (2016, edn.), pp.

8 Haartveit, D.G., Semini, M., and Alfnes, E.: 'Integration Alternatives for Ship Designers and Shipyards', in Frick, J., and Laugen, B. (Eds.): 'Advances in Production Management Systems. Value Networks: Innovation, Technologies, and Management' (Springer Berlin Heidelberg, 2012), pp. 309-316

9 Gosling, J., Towill, D., Naim, M.M., and Dainty, A.: 'Principles for the design and operation of engineer-to-order supply chains in the construction sector ', Production Planning \& Control, 2015, 26, (3), pp. 203-218

10 Bosch-Rekveldt, M.: 'Managing project complexity: A study into adapting early project phases to improve project performance in large engineering projects', Delft University of Technology, 2011

11 Fernandez, D.J., and Fernandez, J.D.: 'Agile Project Management - Agilism Versus Traditional Approaches ', Journal of Computer Information Systems, 2009, 49, (2), pp. 10-17

12 Kjersem, K., and Emblemsvåg, J.: 'Literature review on planning design and engineering activities in shipbuilding'. Proc. IGLC 22, Oslo2014 pp. Pages

13 Kerzner, H.: 'Project Management A System Approach to Planning, Scheduling, and Controlling' (2013a, Eleventh edition edn. 2013a)

14 Jünge, G.H., Kjersem, K., Alfnes, E., and Andersen, B.: 'The maturity of ETO project planning and control', in Editor (Ed.)^(Eds.): 'Book The maturity of ETO project planning and control' (2016, edn.), pp.

15 Ciobanu, I.C., and Neupane, G.P.: 'Phase-Based Project Management at Aker Yards: A Lean Shipbuilding Perspective', Molde University College 2008

16 Voss, C., Tsikriktsis, N., and Frolich, M.: 'Case research in operations management', International Journal of Operations \& Production Management, 2002, 22, (2), pp. 195-219

17 Yin, R.K.: 'Case Study Research: Design and Methods ' (Sage Publications, Inc. , 2014, 5th edn. 2014)

18 Van Aken, J.E., and Romme, G.: 'Reinventing the future: adding design science to the repertoire of organization and management studies', Organization Management Journal, 2009, 6, (1), pp. 5-12

19 Eisenhardt, K.M.: 'Building theories from case study research', Academy of management review, 1989, 14, (4), pp. 532-550

20 Mello, M.H.: 'Coordinating an engineer-to-order supply chain - A study of shipbuilding projects', Norwegian University of Science and Technology 2015

21 Emblemsvåg, J.: 'Lean Project Planning: Using lean principles in project planning ', International Journal of Construction Project Management 2014a 